\title{
QUALITY IN GENERAL PRACTICE
}

\author{
LT COL W G KILPATRICK, MB, MRCGP, D(Obst) RCOG, RAMC \\ CAPT J CARROLL, MB, BS, D(Obst) RCOG, RAMC \\ FLT LT A MARTIN, MB, RAF
}

\section{Introduction}

This paper reports the first of a series of trainee general practitioner meetings held in 1978 for the practices in Hong Kong. It was presented by Kowloon Group Practice and the meeting was recorded on tape and later edited.

The opening remarks by Col. Kilpatrick indicated that this was a new venture, in part a trainee project and in part a forum for all the trainees and trainers from the Hong Kong practices.

The audience was reminded that Honingsbaum ${ }^{1}$ severely criticized standards in British general practice. He produced a sharp reaction from many general practitioners (GPs) but there is no doubt that he shook some strongly entrenched views, and inspired some re-thinking. The aim of high quality general practice (GP) was behind the emergence of the Royal College of General Practitioners in 1952 and the idea of vocational training. It was widely recognised that many doctors aimed for high standards but relatively few consistently obtained them.

\section{Quality in general practice}

In recent years the concept of audit, either self-imposed or imposed by an outside body has been mooted; and it seems logical that such an audit should be initiated from within the discipline and be a continuing process. Until recently 'audit' has been seen mainly as a disciplinary exercise involving for example the General Medical Council, the Ombudsman or the Patients Association. In all these instances a failure of duty was involved but the new aim was for a positive attempt, by common consent, to attain and maintain the highest degree of competence in G.P.

Medical care must meet certain criteria; it must be both accessible and acceptable to the whole population, able to identify the medical needs of the whole population and make the optimum use of available medical facilities. But two questions remain in regard to the basis of medical care in GP. dards?

(a) What is good practice? (b) How do we maintain and improve our stan-

\section{What is good practice?}

Capt Carroll began by posing the question "Is there excellence in GP? establishing the theme that the definition of quality care is exceedingly difficult and means different things to different practitioners and their patients. He found it easier to define the best material facilities in a practice rather than the best methods of patient care. Various characteristics of doctors were suggested showing that most doctors provide a service in a highly personal way.

\section{Discussion}

A division of opinion was shown over the question of postgraduate qualifications and whether motivation is more important than the qualification itself.

Col. Edgington felt that a desire for high standards often resulted in taking higher qualifications and the presence of that desire could constitute evidence of proper training. Some dissent was expressed on the question of whether vocational 
training is essential, whilst Sqdn Ldr Pike felt that, in general, while it would in the long term improve general practitioner standards, there are GPs of high quality who have never been vocationally trained. Lt Col Billinghurst suggested that although clinical knowledge is of paramount importance, a 'caring' attitude matters to a significant degree.

\section{Doctor-patient relationship}

Capt Carroll continued by suggesting that quality care in GP is 80 per cent the result of a good doctor-patient relationship. Many factors of influences were illustrated, and the patient was considered as both an individual and as part of the community. The 'Ivory Tower' attitude of exclusive retreat into the doctor-patient relationship as the total answer must be balanced by the requirement for the doctor to work in society with social services, police and other bodies. He argued for respecting confidentiality and the inherent requirement for the doctor to remain an individual despite the importance that society places on his approach to general issues like abortion, smoking and sexual attitudes.

Discussion

The importance of 'caring' and knowledge stimulated argument, as did the degree of importance of the doctor-patient relationship in measuring quality care. It was felt that 'caring' is more difficult to acquire than knowledge; to some it is a natural characteristic whereas others need guidance to understand and develop it. It was suggested that the ability to 'care' is part of the art of GP while knowledge is the science, and vocational training should include both. Surg Cdr Forsyth felt that caring was no substitute for knowledge and that accurate knowledge reduced the need to emphasize 'care,' and he said "Too much 'caring' is the result of inadequate knowledge."

\section{Transactional analysis}

The final part of Capt. Carroll's argument looked further into the doctor-patient relationship, as understood by transactional analysis: He felt that the basic needs of a high quality of practice are having a good relationship, knowing the requirements initially, knowing what is required to maintain them, but also to be able to measure results.

He ended by admitting the difficulty of measuring standards in practice, the difficulty of ever-increasing medical knowledge and its therapeutic implication, particularly when providing for people and not for recipients of disease.

\section{Discussion}

Capt Carroll suggested that perhaps GPs should be taught to assume roles rather than show their natural individual weaknesses. After some discussion around the importance of transactional analysis in understanding consultations, Col. Kilpatrick pointed out that a survey by Irvine ${ }^{2}$ had tried to define the ideal practice by giving points for various aspects such as equipment, staff, doctor's qualification, but that no emphasis had been laid on the very important aspect of ability by the doctor to communicate with his patients. It was evident that the meeting felt that this was a serious omission.

How do we improve and maintain standards in general practice?

Flt Lt Martin began by indicating that he would not cover the subject of maintenance of quality in depth, hoping that the detail would appear during the general discussion. He said there are two spheres of influence in the Services: that of the normal doctor and that resulting from the special requirements of the serviceman 
and his family. He illustrated the differences between civilian and Service practice pointing out that the limited spectrum of disease was compensated by the greater time that can be spent with the patients in consultation. He warned that overspending of time on one patient to the detriment of others is not good practice, and efficient organisation is an important element of medical care. Ideally one should be able to design one's own working conditions because one works best in the environment suited to one's needs - not always easy in the Service situation. It also requires the agreement of partners and colleagues, as harmony between colleagues is also an important part of quality care.

He went on to describe how design of surgeries, amenities in examination rooms, arrangements for consultation sessions, appointments, special clinics, emergencies and home visits, and also the availability of laboratory services, all affect the standard of care. The easy retrieval of records, the existence of a diagnostic index and an age-sex register could be important. He showed how the experiences of Service medical officers in different practices are of practical value and can be applied to good effect.

\section{Medical standards}

This must include not only a revision of existing techniques but also keeping up with new developments. The simplest method is day to day discussion with partners. Postgraduate teaching is available and the close contact between Service doctors and their Service hospitals compares very favourably with the situation in civilian practice.

The largest source of facts, he felt, but not always the easiest to use is literature. It is simple to lay aside with a mental promise to look at it another day. $\mathrm{He}$ preferred Winthrop medicassettes to those of the Medical Recording Service Foundation which are often less up-to-date.

\section{Audit}

He included under this heading a wide range of activities from patient feedback to multicentre trials conducted over several years. Audit is the only way to assess the results of new methods in a reasonably objective fashion. Mourin divided audit into three components:-

(a) The setting of standards. (b) Assessment of performance. (c) Modification of clinical practice, in summary, to educate and plan.

He ended by discussing membership of professional bodies dividing them into those which require a clinical examination for membership and those concerned with the wider aspects of medicine, for example, The British Medical Association (BMA). However, he noted, letters after a name are hardly a guide to the qualities of a doctor, though membership at least allows one to make use of further facilities to help monitor one's standards.

He showed how those bodies can influence medical opinion, the joint RCGP \& RCOG study on oral contraceptives being a good example. Influence of a different kind in the political arena was exerted by the BMA and others, in "Does not a doctor who is contented with his lot, work better and provide a higher quality of care for his patient?".

\section{Discussion}

Considerable interest was shown in discussion over Mourin's concept of the three components of audit.

Flt Lt Martin wondered if the others agreed with him when he put research under audit, he felt that it is an important factor in audit because of the influence on changing one's own clinical practices in the light of other peoples experience. 
Sqn Ldr Pike commented that many GPs are very resistant to change in their methods because they felt secure in them, but this did not mean that their patients are happy or well served. Col. Edgington confirmed this, referring to a study in which it was found that doctors become more resistant to change as they get older. Capt Lowe felt that we all have our own data base and we do not like changing it, as it upsets our status quo. Capt Carroll argued that we must take notice of other peoples audit. We are most reluctant to change, he said, but Capt Lowe considered that it is our data base that we do not like changing, that is, the fundamental store of medical knowledge.

Capt Lowe raised the specific dilemma of junior partners considering that there is something wrong with the way in which the senior partner is practising. Should they suggest he resign?

There was eventually a concensus of opinion that this depended solely on what was good for the patients and the practice. No one suggested who should "bell the cat"! Flt Lt Cummings, added a cautionary note, felt that a person thought to be potentially dangerous could be using new ideas which might later turn out to be acsepted practice. Criticism in such an instance could be stifling research.

The use of a financial audit in a practice in the North of England was mentioned. In this case a decision to reduce their drug bill resulted in a saving of 15 to 20 per cent. Col Edgington felt that this affected only their drug bill, whereas a survey over the country three years ago, showed that there was a factor of three between the highest and lowest spending practice.

Capt Heap was concerned that by reducing the drug bill, one could underprescribe good drugs which happen to be expensive, for purely financial reasons. Flt Lt Martin suggested that a way of saving money could be to reduce the period of prescribing as it is well known that patients hoard drugs-presumably the left-overs from over-long courses.

An example was used by Sqdn Ldr Pike in the treatment of urine infection in women; only 45 per cent have significant bacteriuria. Eighty per cent of the organisms are sensitive to sulphonamides, ninety-five per cent are sensitive to Septrin. Septrin costs $£ 1.50$ a course, Urolucosil $28 \mathrm{p}$ a course. What is the drug of choice Urolucosil, Septrin or nothing?

\section{Conclusion}

In the last session Col Kilpatrick introduced a fictional example of some of the problems in setting up a new civilian practice. Those present gave their views of how the doctor might tackle the problems in relation to the subject of the meeting. These included proper recording of medical notes, repeat prescriptions, analysis of a practice and attributes to a partner. With this discussion the meeting ended.

\section{Acknowledgements}

The meeting organisers are indebted to Col. Edgington, Deputy Director of Medical Services and Commanding Officer, British Military Hospital, Hong Kong for permission to hold the meeting in the hospital, and to Lt Col Billinghurst, course organiser for Vocational Training in General Practice for help and encouragement in arranging the meeting. They are also indebted to Cpl A Kumor QARANC for transcribing the tape recording.

1. Honigsbaum, F (1972). Journal of the Royal College of General Practitioners 22, 429-451.

2. IRVINE, D (1972). Journal of the Royal College of General Practitioners. Report from General Practice. No. 15. Teaching Practices.

3. Mourvin, K (1976). Journal of the Royal College of General Practitioners. 26, 726-733. Editor's Note: This article was first submitted for publication in September 1978. Consequently, on advice, an Editorial decision was made to 'Up-date'. 